Supporting Information

\title{
Green production of phthalic anhydride from bio-based furan and maleic anhydride by an acid resin catalyst
}

Xiaojie Shao, ${ }^{\text {a,b,c }}$ Lijuan Su, ${ }^{\text {a,b,c }}$ Jiaojiao Zhang, ${ }^{\text {a,b,c }}$ Zishang Tian, ${ }^{\text {a,b,c }}$ Ning Zhang, ${ }^{\text {a,b,c }}$

Yingxiong Wang, ${ }^{\mathrm{a}, \mathrm{b}, \mathrm{c}}$ Hongliang Wang, ${ }^{\mathrm{d}}$ Xiaojing Cui,,${ }^{\mathrm{e}}{ }^{*}$ Xianglin Hou, $, \mathrm{a}, \mathrm{b}, \mathrm{c},{ }^{*}$

Tiansheng Deng, a,c,*

a Shanxi Engineering Research Center of Biorefinery, Institute of Coal Chemistry,

Chinese Academy of Sciences, 27 South Taoyuan Road, Taiyuan 030001, China

${ }^{\mathrm{b}}$ Center of Materials Science and Optoelectronics Engineering, University of Chinese Academy of Sciences, Beijing 100049, China

c CAS key laboratory of carbon materials, Institute of Coal Chemistry, Chinese Academy of Sciences, 27 South Taoyuan Road, Taiyuan 030001, China.

d Center of Biomass Engineering/ College of Agronomy and Biotechnology, China Agricultural university, Beijing 100193, China

e Institute of Interface Chemistry and Engineering, Department of Chemistry and Chemical Engineering, Taiyuan Institute of Technology, Taiyuan, Shanxi, 030008,

China

* Corresponding Author E-mail: dts117@sxicc.ac.cn (T. S. Deng);

cxjtyut@126.com (X. J. Cui);

houxl@sxicc.ac.cn (X. L. Hou).

Number of pages: 9

Number of Figures: 9

Number of Tables: 3 


\section{Content}

Figure S1. $\mathrm{N}_{2}$ adsorption-desorption isotherms and pore size distribution curves of resins.

Figure S2. ${ }^{1} \mathrm{H}$ NMR spectrum of purified DA adduct.

Figure S3. ${ }^{1} \mathrm{H}$ NMR spectrum of dehydration reaction products.

Figure S4. ${ }^{1} \mathrm{H}$ NMR spectrum of ASA generated by MSA and AA.

Figure S5. Possible reaction on pretreatment of Amberlyst 36 with AA.

Figure S6. Quantification analysis of the percentage of ASA produced by the reaction of sulfonic groups and AA.

Figure S7. Investigation of adsorption of DA adduct on the neutralized Amberlyst 36.

Figure S8. Different treatments to the reusability of Amberlyst 36 in DA adduct dehydration to PA.

Figure S9. Investigation the changes of model catalyst p-TSA reaction with AA.

Table S1. Performances of MSA for DA adduct dehydration to PA.

Table S2. The effect of catalyst dosages for DA adduct dehydration to PA.

Table S3. Effect of water content of catalyst on the yield of ASA. 

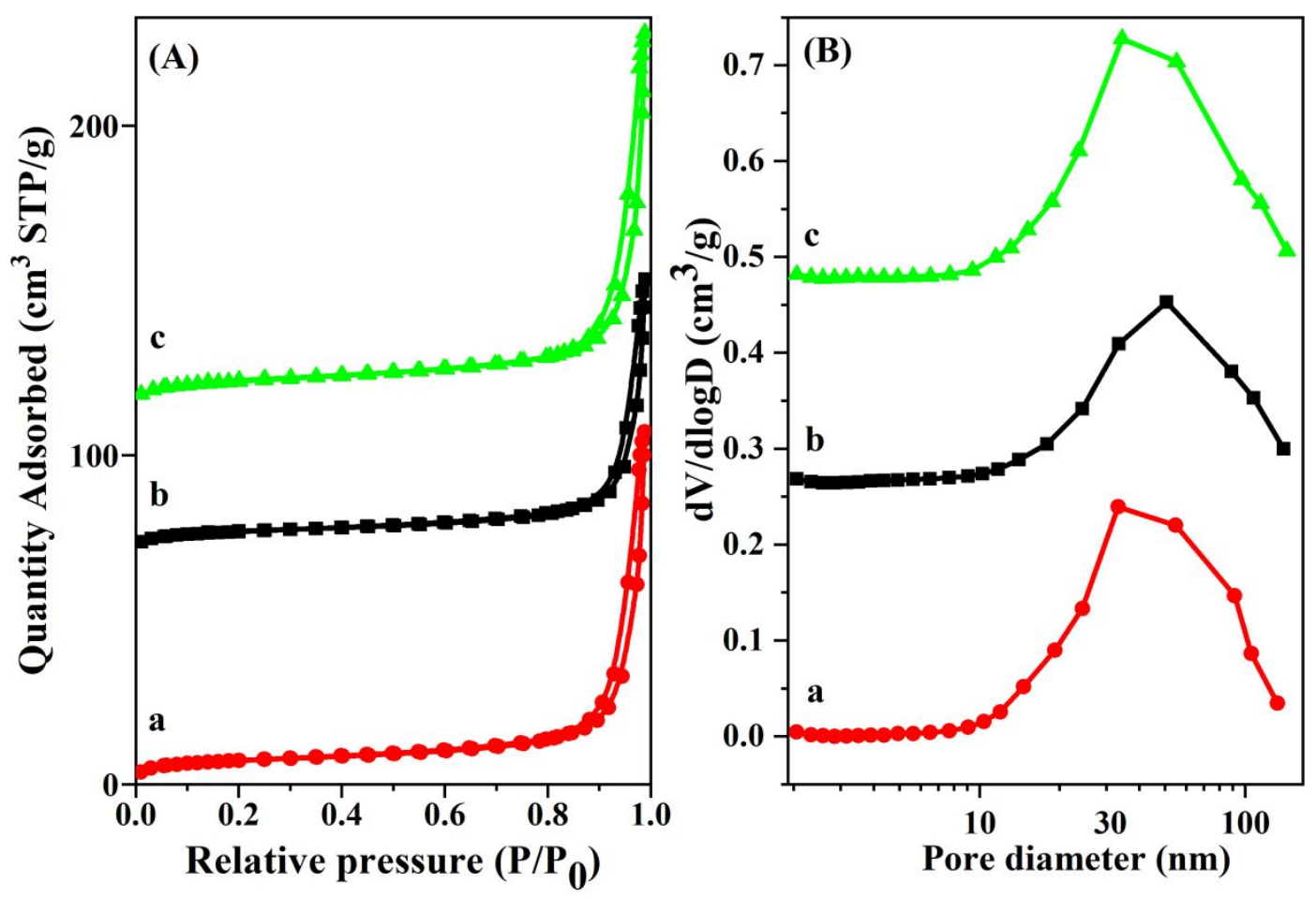

Figure S1. (A) $\mathrm{N}_{2}$ adsorption-desorption isotherms and (B) pore size distribution curves of (a) Amberlyst 36, (b) Amberlyst 35, (c) Amberlyst-15.

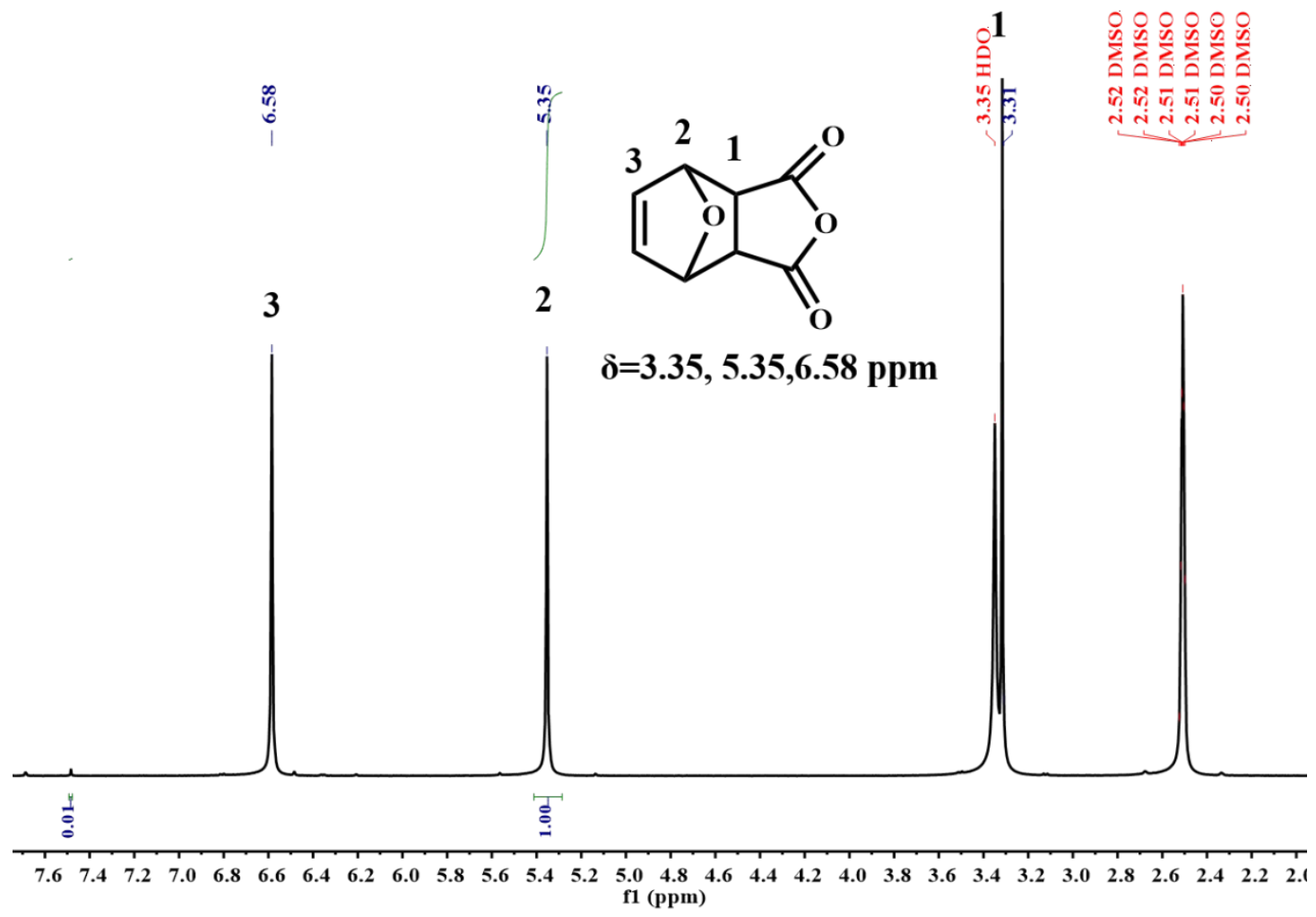

Figure S2. ${ }^{1} \mathrm{H}$ NMR spectrum of purified DA adduct. 


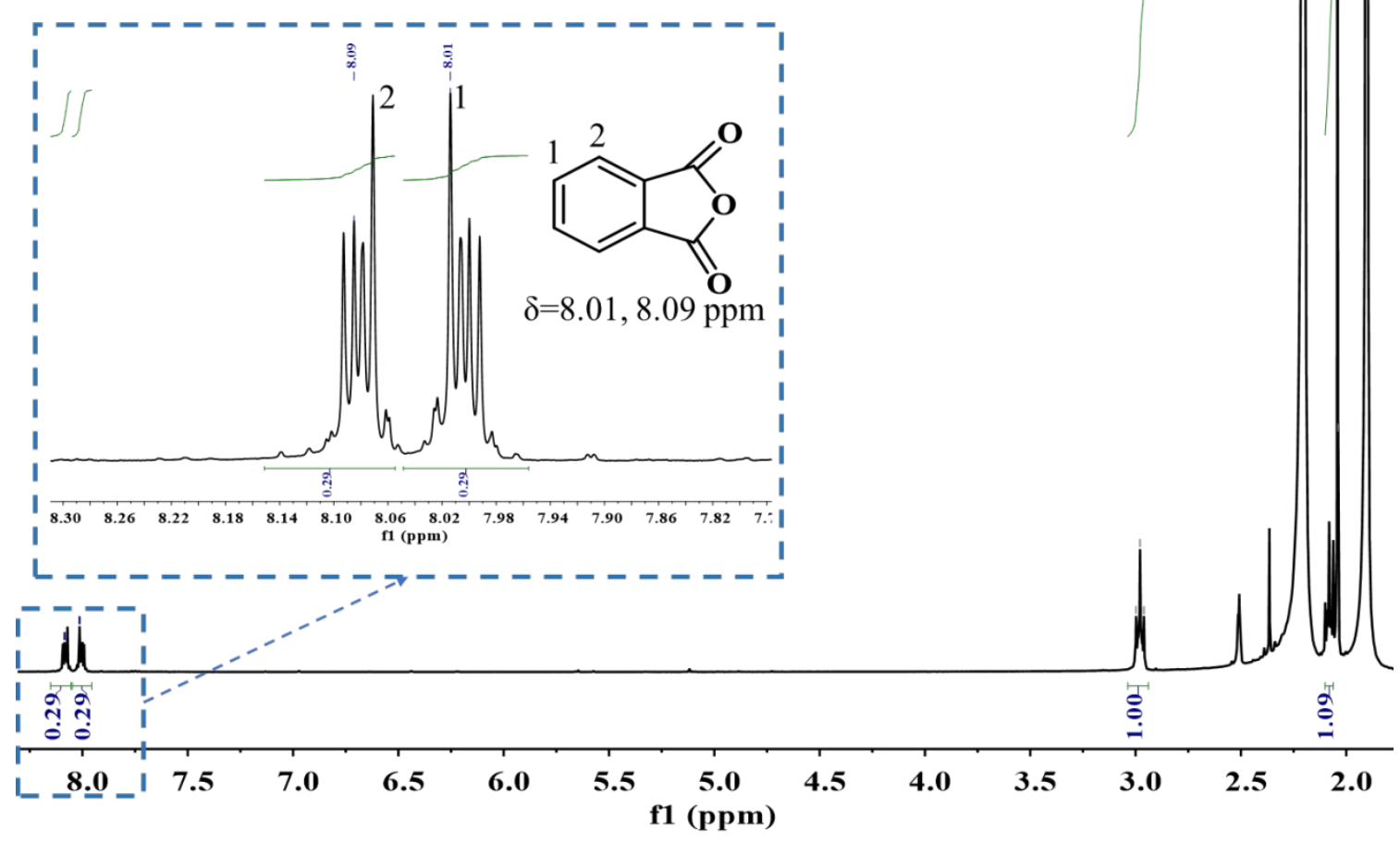

Figure S3. ${ }^{1} \mathrm{H}$ NMR spectrum of dehydration reaction products.

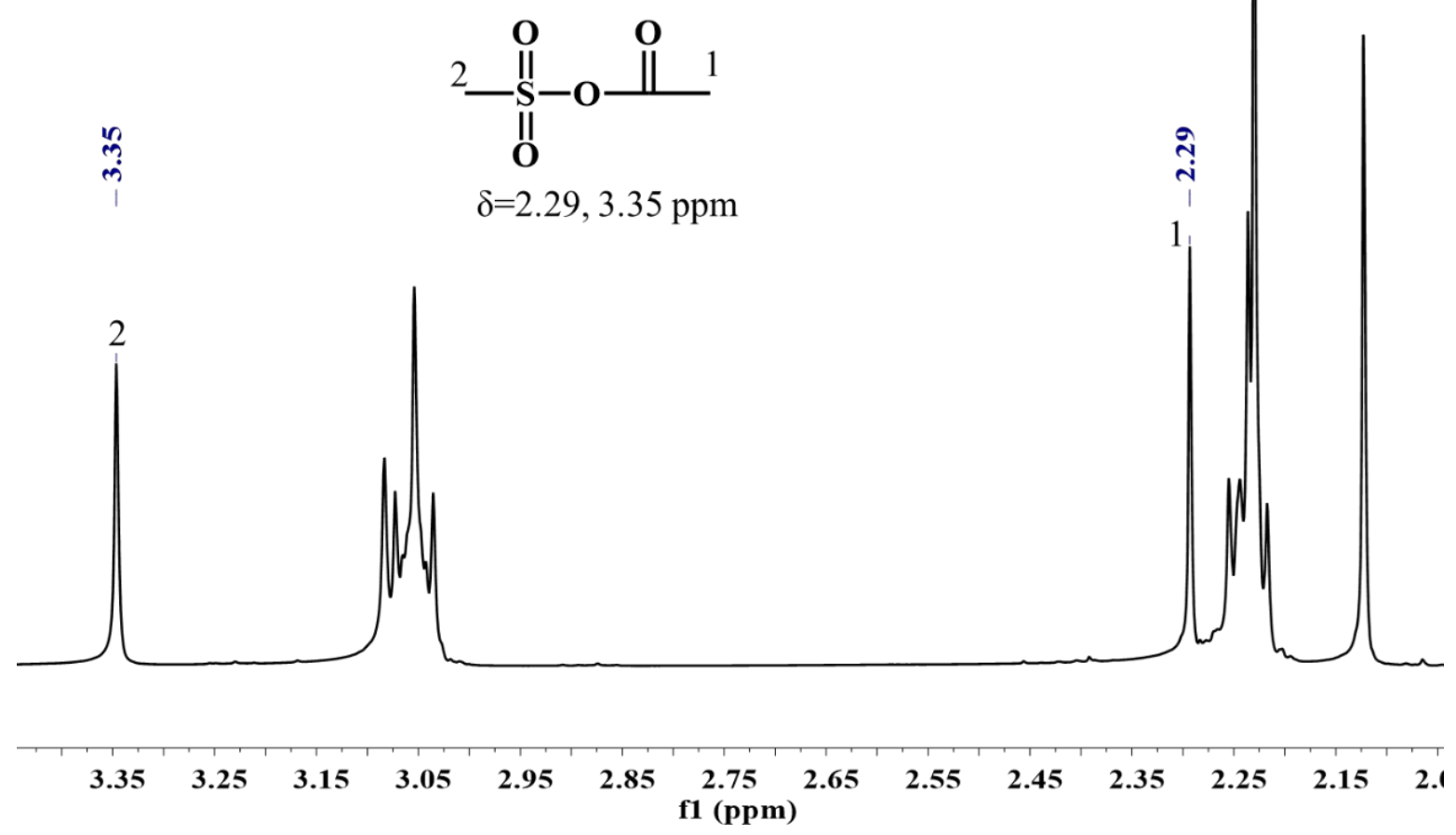

Figure S4. ${ }^{1} \mathrm{H}$ NMR spectrum of ASA generated by MSA and AA. 


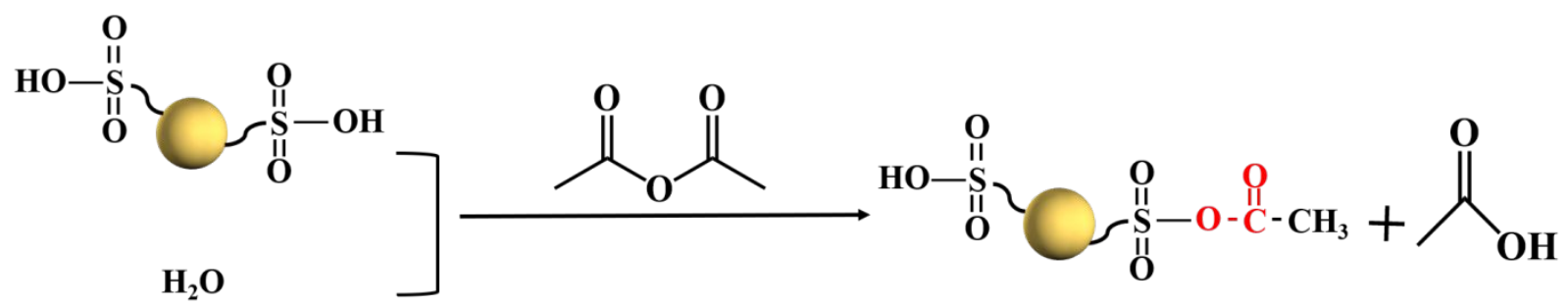

Figure S5. Possible reaction on pretreatment of Amberlyst 36 with AA.

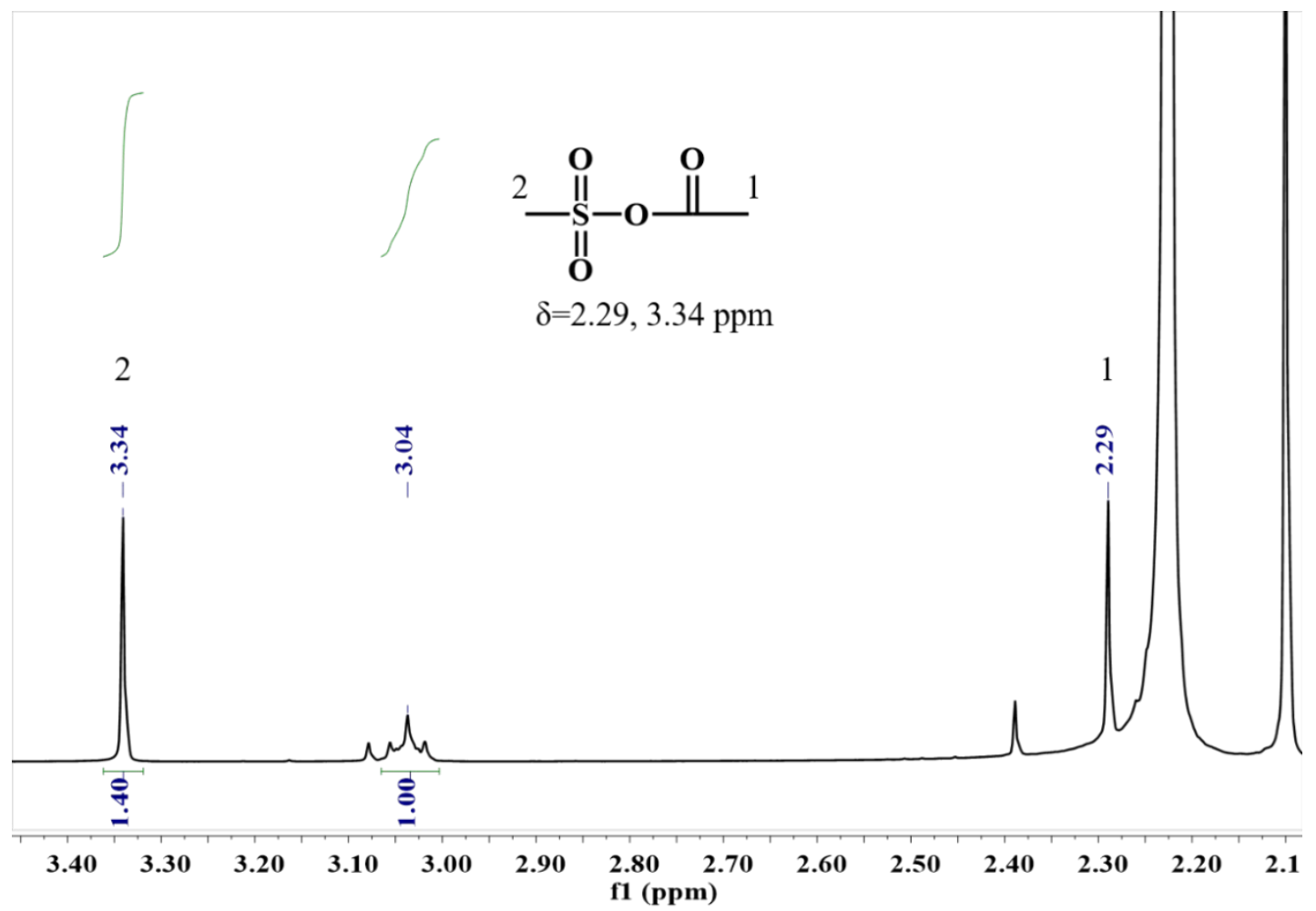

Figure S6. Quantification analysis of the percentage of ASA produced by the reaction of sulfonic groups and AA. Reaction conditions: 2.39 mmol of MSA, $12.8698 \mathrm{~g}$ of AA, $1.248 \mathrm{mmol}$ of sulfolane, reaction at R.T. for $5 \mathrm{~min}$. 


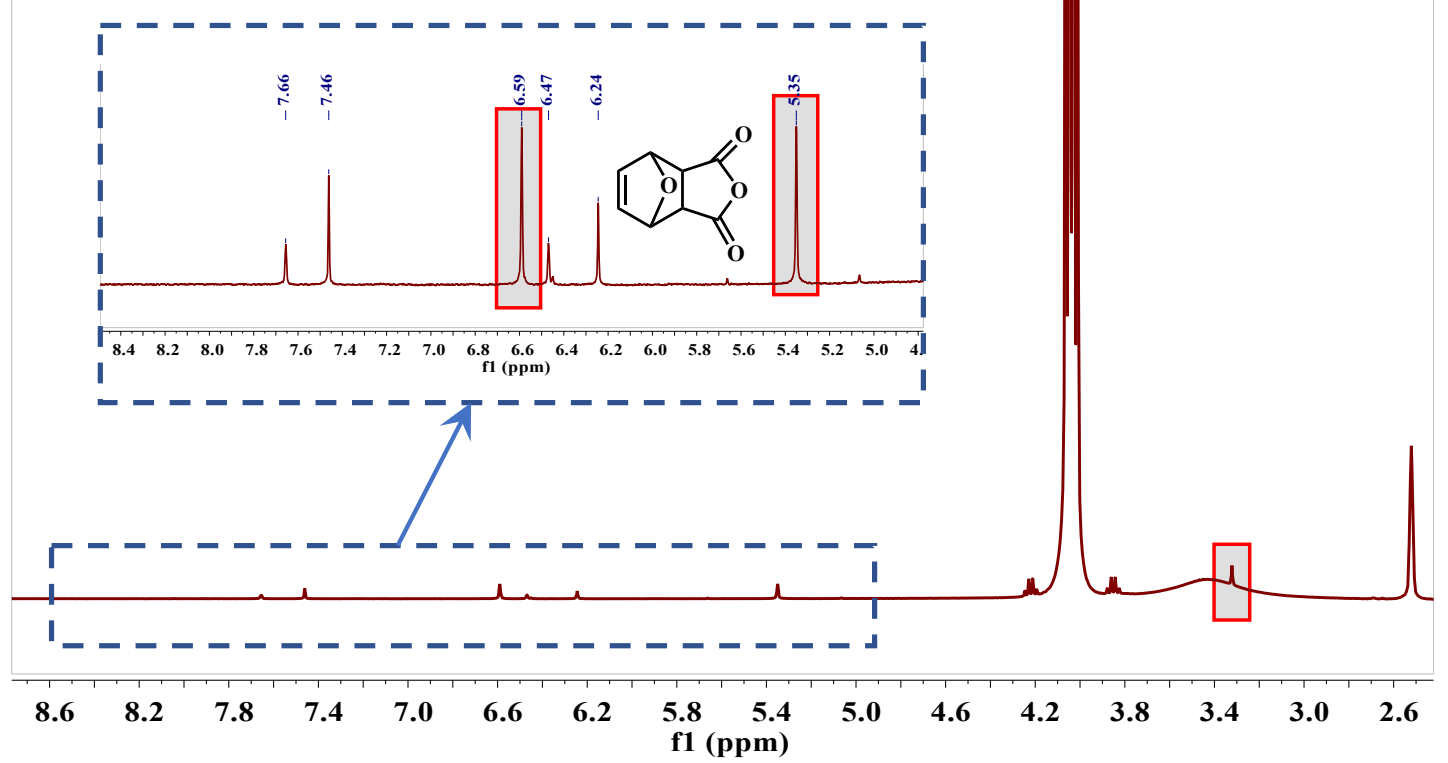

Figure S7. Investigation of adsorption of DA adduct on the neutralized Amberlyst 36.

Reaction conditions: After the adsorption experiment on the neutralized Amberlyst 36 , the resin with the adsorbed DA adduct on it was collected by filtration, and then washed by ethyl acetate.

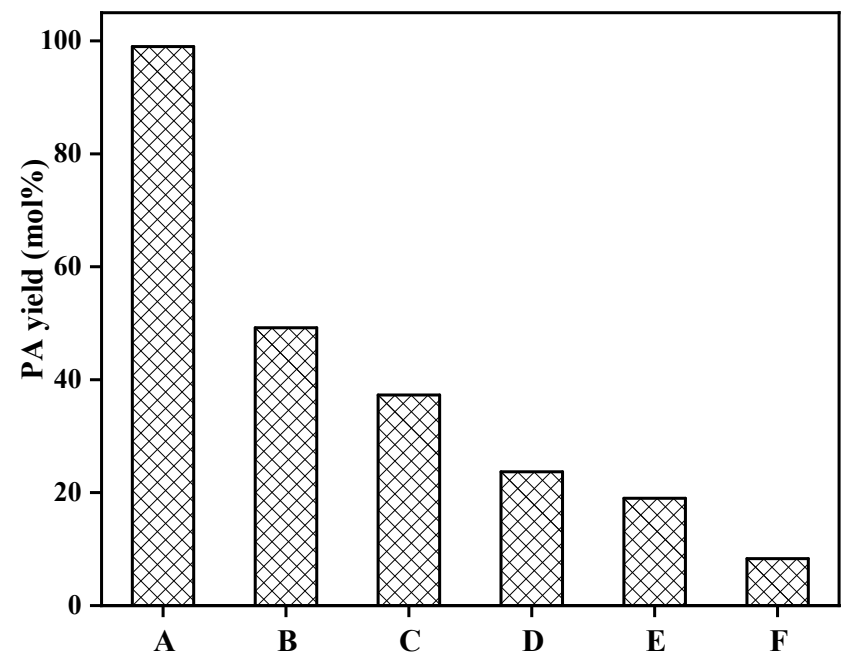

Figure S8. Different treatments to the reusability of Amberlyst 36 in DA adduct dehydration to PA. (A) Fresh catalyst, (B) Methanol washed, and then $100{ }^{\circ} \mathrm{C}$ for 30 
min in distilled water and Acid regenerated, (C) Methanol washed and Acid regenerated, (D) Methanol washed, (E) Methanol washed and dried, and then $100{ }^{\circ} \mathrm{C}$ for 30 min in $\mathrm{Na}_{2} \mathrm{CO}_{3}$ and Acid regenerated, (F) AA washed. Reaction conditions: 450 mg used catalyst soaked in AA at $3{ }^{\circ} \mathrm{C}$ for $3 \mathrm{~h}$ in advance, AA $400 \mathrm{mg}$, sulfolane 0.22 mmol, DA adduct $0.13 \mathrm{mmol}, 25^{\circ} \mathrm{C}$ for $2 \mathrm{~h}$ followed by a temperature increase to $90{ }^{\circ} \mathrm{C}$ for $1 \mathrm{~h}$.

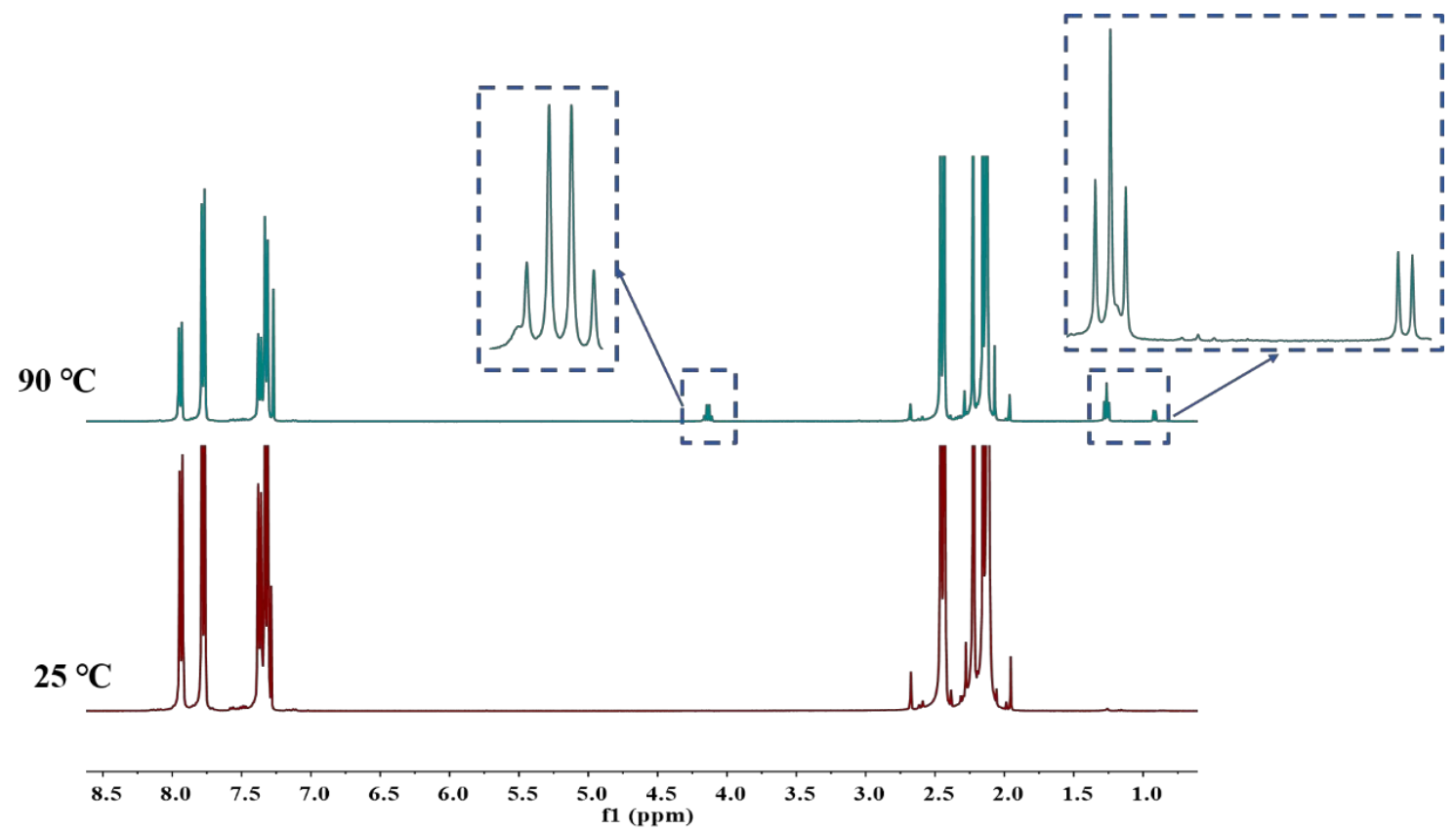

Figure S9. Investigation the changes of model catalyst p-TSA reaction with AA. (a) $\mathrm{n}_{(\mathrm{AA})}: \mathrm{n}_{(\mathrm{p}-\mathrm{TSA})}=1: 1,25^{\circ} \mathrm{C}, 20 \mathrm{~min},(\mathrm{~b}) \mathrm{n}_{(\mathrm{AA})}: \mathrm{n}_{(\mathrm{p}-\mathrm{TSA})}=1: 1,25^{\circ} \mathrm{C}$ for $2 \mathrm{~h}$ followed by a temperature increase to $90{ }^{\circ} \mathrm{C}$ for $1 \mathrm{~h}$. 
Table S1. Performances of MSA for DA adduct dehydration to PA. ${ }^{\text {a }}$

\begin{tabular}{ccccc}
\hline \multirow{2}{*}{ Entry } & Catalyst & Solvent & \multicolumn{2}{c}{ Performance } \\
\cline { 4 - 5 } & & & Conv. (\%) & Selectivity (\%) \\
\hline 1 & $\mathrm{CH}_{3} \mathrm{SO}_{3} \mathrm{H}$ & $\left(\mathrm{CH}_{3} \mathrm{O}\right)_{2} \mathrm{O}$ & 100 & $80.0^{1}$ \\
2 & $\mathrm{CH}_{3} \mathrm{SO}_{3} \mathrm{H}$ & $\left(\mathrm{CH}_{3} \mathrm{O}\right)_{2} \mathrm{O}$ & 100 & 74.9 \\
\hline
\end{tabular}

${ }^{\text {a }}$ reaction conditions: DA adduct $3.01 \mathrm{mmol}$, MSA $31 \mathrm{mmol}$, acetic anhydride 5.50 mmol, $25^{\circ} \mathrm{C}$ for $2 \mathrm{~h}$ followed by a temperature increase to $80^{\circ} \mathrm{C}$ for $4 \mathrm{~h}$.

Table S2. The effect of catalyst dosages for DA adduct dehydration to PA. ${ }^{\text {a }}$

\begin{tabular}{llllll}
\hline \multirow{2}{*}{ Entry } & Catalyst & \multicolumn{5}{c}{ Mass (g) } \\
\cline { 3 - 5 } & & 0.45 & 0.5 & 0.55 & 0.6 \\
\hline 1 & Amberlyst 36 & $99.0 \mathrm{~mol} \%$ & - & - \\
2 & Amberlyst 35 & $72.2 \mathrm{~mol} \%$ & $98.5 \mathrm{~mol} \%$ & - \\
3 & Amberlyst 15 & $67.2 \mathrm{~mol} \%$ & $78.2 \mathrm{~mol} \%$ & $82.4 \mathrm{~mol} \%$ & $84.1 \mathrm{~mol} \%$ \\
\hline
\end{tabular}

a Reaction conditions: catalyst soaked in AA at $3{ }^{\circ} \mathrm{C}$ for $3 \mathrm{~h}$ in advance, AA $400 \mathrm{mg}$, sulfolane $0.22 \mathrm{mmol}$, DA adduct $0.13 \mathrm{mmol}, 25^{\circ} \mathrm{C}$ for $2 \mathrm{~h}$ followed by a temperature increase to $90^{\circ} \mathrm{C}$ for $1 \mathrm{~h}$.

Table S3. Effect of water content of catalyst on the yield of ASA.

\begin{tabular}{ccc}
\hline Entry & $\mathrm{n}_{\mathrm{MSA}} / \mathrm{n}_{\mathrm{AA}}$ & Yield (mol\%) \\
\hline $1^{[\mathrm{a}]}$ & 1.1 & 45.1 \\
$2^{[\mathrm{b}]}$ & 1.1 & 10.6 \\
\hline
\end{tabular}

${ }^{\text {a }}$ reaction conditions: MSA $6.14 \mathrm{mmol}$, AA $5.66 \mathrm{mmol}, 25^{\circ} \mathrm{C}$ for $5 \mathrm{~min}$.

${ }^{\mathrm{b}}$ MSA $6.14 \mathrm{mmol}$, AA $5.66 \mathrm{mmol}, 2.9 \mathrm{wt} . \%$ water was added to the system, $25^{\circ} \mathrm{C}$ for $5 \mathrm{~min}$. 


\section{References}

1. Mahmoud, E.; Watson, D. A.; Lobo, R. F., Renewable production of phthalic anhydride from biomass-derived furan and maleic anhydride. Green Chem. 2014, 16 (1), 167-175, DOI: $10.1039 / \mathrm{c} 3 \mathrm{gc} 41655 \mathrm{k}$. 